\title{
Carbon Fibers Derived from Pure Alkali Lignin Fibers Through Electrospinning with Carbonization
}

\author{
Tunnapat Worarutariyachai ${ }^{\mathrm{a}, \mathrm{b}}$ and Surawut Chuangchote ${ }^{\mathrm{c}, \mathrm{d}, *}$

\begin{abstract}
Alkali lignin $(A L)$ fibers with a smooth surface and fine morphological appearance were successfully produced via electrospinning using a simple heated single spinneret system, instead of typical electrospinning of lignin with added synthetic polymer blends or conventional co-axial electrospinning. To reduce the size of the fibers, glycerol was added to the spinning solution as a co-solvent for surface tension reduction and electrospinnability improvement. After electrospinning, stabilization and carbonization were subsequently performed to convert $A L$ fibers to carbon fibers (CFs). The obtained CFs displayed rough and uneven surfaces. However, the CFs derived from glycerol-added solution showed greater electrical conductivity, specific surface area, and porosity compared with those from pure AL solution. Furthermore, the results indicated that the inorganic salts on the rough surface of CFs were successfully removed by sulfuric acid $\left(\mathrm{H}_{2} \mathrm{SO}_{4}\right)$ washing. After $\mathrm{H}_{2} \mathrm{SO}_{4}$ washing, the CFs revealed a smoother surface and higher electrical conductivity, specific surface area, and porosity.
\end{abstract}

Keywords: Carbon fibers; Alkali lignin; Electrospinning; Carbonization; Electrical conductivity

Contact information: a: The Joint Graduate School of Energy and Environment, King Mongkut's University of Technology Thonburi, 126 Prachauthit Rd., Bangmod, Thungkru, Bangkok 10140, Thailand; b: Center for Energy Technology and Environment, Ministry of Education, Bangmod, Thungkru, Bangkok, Thailand; c: Department of Tool and Materials Engineering, Faculty of Engineering, King Mongkut's University of Technology Thonburi, Bangmod, Thungkru, Bangkok, Thailand; d: Research Center of Advanced Materials for Energy and Environmental Technology (MEET), King Mongkut's University of Technology Thonburi, Bangmod, Thungkru, Bangkok, Thailand;

*Corresponding author: surawut.chu@ kmutt.ac.th

\section{INTRODUCTION}

Carbon fibers (CFs) are carbon materials that contain more than $95 \%$ carbon and have a lamellar graphite-like structure, possessing unique properties (i.e., chemical, mechanical, and electrical) including light weight, high tensile modulus and strength, and high thermal or electrical conductivity (Svinterikos and Zuburtikudis 2016). These properties enable them to be widely used in many fields of applications, such as automotive and aerospace industries (Dai et al. 2018), and composites (Matsuo 2008).

The global requirement of CFs has particularly increased, of which most of the requirement is in the automotive and aerospace industries (Jacob 2014). Their excellent lightweight character helps improve fuel efficiency and offset battery weight (Adam 1997; Jacob 2014). Moreover, advanced technologies have recently improved various properties of CFs by reducing their diameter, and resulting CFs also have been utilized in other interesting applications, such as filtration technology (Thiruvenkatachari et al. 2009), catalysis (Yang et al. 2015), and electrochemical energy storages (Javaid 2017).

Currently, commercial CFs have been produced from petroleum-based resources (i.e., polyacrylonitrile (PAN) or pitch) as main precursors that are relatively expensive and 
not environmentally friendly. However, their high cost and limited supply of precursors are important problems of CFs for practical applications (Baker and Rials 2013; Wang et al. 2013). Therefore, many researchers are searching for alternative precursor materials that are low-cost and environmentally friendly to produce CFs with acceptable properties compared with the petroleum-based ones (Sen et al. 2015; Berenguer et al. 2016).

Among renewable biomass-based precursors, lignin has been actively considered as a low cost precursor for CFs production, because it is a natural biomass source with aromatic properties (Kai et al. 2015). The chemical structure of lignin is complex, containing random networks of phenylpropane groups that are composed of carbon, hydrogen, and oxygen. Its monomeric units are $p$-coumaryl alcohol, coniferyl alcohol, and sinapyl alcohol (Duval and Lawoko 2014). The ratio of each monomeric unit depends mainly on the different species of plant (Lora and Glasser 2002; Duval and Lawoko 2014). It is a major by-product that is produced in a large quantity annually in the paper pulping and cellulosic-ethanol industries (Jin et al. 2014). Despite the wide availability of lignin, there is no large-scale industrial utilization for lignin as any special product. Nevertheless, the great availability of lignin enables it to be considered as an interesting precursor for CFs production (Frank et al. 2014).

One of the various methods that have been utilized to produce ultrafine CFs is electrospinning. It has been demonstrated that continuous CFs with controllable diameters can be successfully fabricated. Some electrospun fibers have been converted into CFs (Zhang and Hsieh 2009; Inagaki et al. 2012; Schreiber et al. 2014). In comparison, lignin fiber productions through electrospinning are relatively challenging because lignin solution has unique molecular entanglement, viscosity, surface tension, and rheological behaviors, which are different from typical electrospinnable polymers. Therefore, several reports demonstrated successful electrospinning of lignin with polymer blends (i.e., polyacrylonitrile (PAN) (Ma et al. 2015), polyethylene oxide (PEO) (Dallmeyer et al. 2014; Poursorkhabi et al. 2015), and polyvinyl alcohol (PVA) (Ago et al. 2012)) to improve its electrospinnability.

In the last decade, Ruiz-Rosas et al. (2010) successfully produced fibers from pure organosolv lignin (produced from organosolv process, a pulping technique that uses an organic solvent to solubilize lignin and hemicellulose) via co-axial electrospinning, where there was a sheath layer of solvent in the co-axial spinneret. The organosolv process has been well known in the pulping industry and has a more environmental friendly character than other lignin production processes. However, the limitation of the organosolv process is low capability to apply for the large-scale industry due to economic non-favorability against the competition of their pulping procedure (Chen 2014). On the contrary, the alkali process is one of the predominant global processes and widely accessible at the industrial scale. Therefore, the alkali lignin (AL) (also known as kraft lignin) is the dominant raw material for various studies, readily available and is considerably cheaper than organosolv lignin (Norberg et al. 2013).

Fabrication of ultrafine CFs from AL by electrospinning with some applications have been reported. Hu and Hsieh (2013) reported fabrications of sub-micron activated CFs with high specific surface area by carbonization and activation of electrospun fibers from AL solution blended with PEO. Song et al. (2019) stated that activated CFs could be fabricated by electrospinning of AL/PVA blended solution followed by thermal treatment and activation. The CFs obtained showed a great potential application for absorption of volatile organic compounds (VOCs). From the open literature, there is no previous report on the fabrication of ultrafine CFs derived from pure AL using electrospinning with the 
single-spinneret system. For this reason, this work was performed with the aim to produce CFs from AL without any added synthetic polymer via electrospinning using the single spinneret system with a simple-designed heat method followed by stabilization and carbonization process. The effects of AL solution on the electrospinning performance were explored. After carbonization, the morphology and physical properties of CFs obtained were investigated. Removal of inorganic contaminants from CFs was additionally studied.

\section{EXPERIMENTAL}

\section{Materials}

Preparation of lignin solutions

Solutions of AL (Catalog number 471003 (water soluble); Sigma-Aldrich, St. Louis, USA) in deionized (DI) water were prepared with various ratios of lignin to water in the range of $1: 1$ to $1: 2(\mathrm{w} / \mathrm{w})$ under constant stirring. To increase the electrospinnability of the solutions, glycerol (Chemipan Corporation Co., Ltd., Bangkok, Thailand) was used as a co-solvent. The ratios of glycerol to DI water of $0.5: 1$ to $1: 1(\mathrm{v} / \mathrm{v})$ were studied.

\section{Methods}

\section{Electrospinning}

The prepared solution was added via a 5 -mL plastic syringe with the $45^{\circ}$-tilted setup from a vertical orientation (Fig. 1). A blunt-end $20 \mathrm{G}$ needle was used for the single spinneret connected to the positive electrode of a high voltage supply. A plastic plate covered with aluminum foil was used as the collector and connected to the ground. An aluminum pipe (wrapped with insulation tape to protect any electrical charge) with inlet and outlet holes (for $80{ }^{\circ} \mathrm{C}$-hot water flows by using a water pump) was used as a heat jacket for electrospinning. The heat jacket was used to cover the plastic syringe to heat the solution during electrospinning (to enhance electrospinnability of the lignin solution). The solution was electrospun under a fixed applied potential of $20 \mathrm{kV}$ at the collection distance of $15 \mathrm{~cm}$. After electrospinning, the electrospun fibers were then air dried.

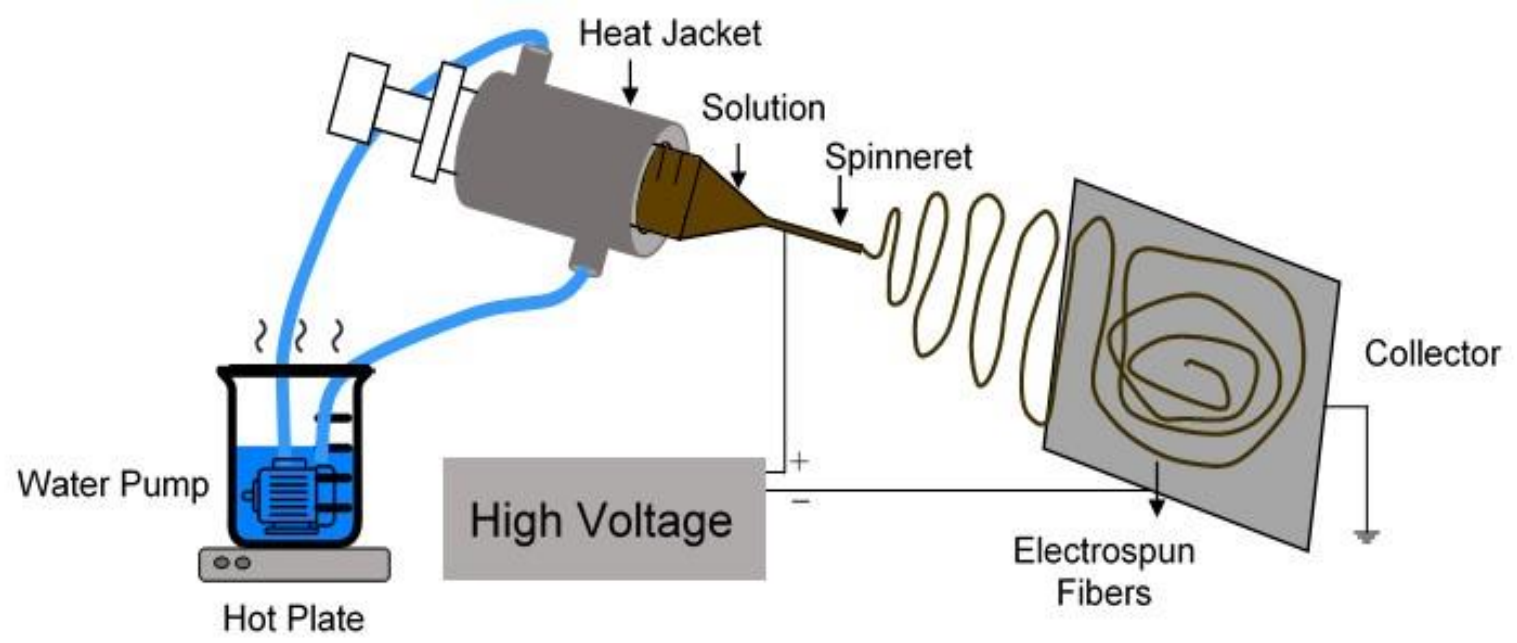

Fig. 1. Schematic illustration of electrospinning procedure of lignin solution with a developed heat jacket 


\section{Thermostabilization and carbonization}

Thermostabilization of the electrospun fibers was completed at $260{ }^{\circ} \mathrm{C}$ for $1 \mathrm{~h}$ with a heating rate of $1{ }^{\circ} \mathrm{C} / \mathrm{min}$. After thermostabilization, the obtained fibers were carbonized under $\mathrm{N}_{2}$ atmosphere at $800{ }^{\circ} \mathrm{C}$ for $1 \mathrm{~h}$ with a heating rate of $5^{\circ} \mathrm{C} / \mathrm{min}$.

\section{Characterizations}

Fiber morphology was investigated using a scanning electron microscope (SEM, JSM-6610LV; JEOL Ltd., Tokyo, Japan). Electron beam energy of $20 \mathrm{kV}$ was used for analysis. The electrospun fibers and stabilized fibers were coated with a gold (Au) layer using a sputter coater (Cressington 108auto; Cressington Scientific Instruments, Watford, UK) before their SEM examination, whereas CFs were imaged without any Au coating. The viscosities of AL solutions were measured with a viscosity meter (Visco Star Plus (type: Visco Star+ L); Fungilab S. A., Barcelona, Spain). The electrical conductivity of CFs was measured at room temperature using a four-point sheet resistivity meter (Fourpoint Meter; Yokogawa, Bangkok, Thailand). The elemental composition of CFs was investigated through energy dispersive x-ray spectroscopy (EDS, INCA X-act; Oxford Instruments, Abingdon, UK) and an elemental analyzer (CHNS/O, LECO 628; LECO Corporation, St. Joseph, MI, USA). The basic chemical characteristics were investigated using a Fourier transform infrared spectrometer (FTIR, Perkin Elmer Spectrum One; PerkinElmer Inc., Waltham, MA, USA). Specific surface area (Brunauer-Emmett-Teller (BET) method) and pore characteristics were examined by $\mathrm{N}_{2}$ adsorption-desorption at 77 K (3Flex Surface Characterization; Micromeritics Instrument Corporation, Norcross, USA).

\section{RESULTS AND DISCUSSION}

\section{Electrospun Fibers}

In order to produce lignin fibers without adding any synthetic polymer under various conditions, it was found that only droplets were observed from most AL solutions in water. This was attributed to low entanglement of lignin molecules because of high viscosity (Dallmeyer et al. 2010). This may be the main reason why there are no reports on electrospinning of purely AL in the literature. Fortunately, at the 1:1.5 w/w ratio of lignin to water, smooth fibers without any beads or droplets with an average fiber diameter of $31.54 \pm 15 \mu \mathrm{m}$ (Fig. 2a) could be electrospun from the heated solution. Chuangchote et al. (2009) reported that the high surface tension of water $(72.2 \mathrm{mN} / \mathrm{m})$ leads to a large diameter of electrospun fibers from aqueous solution. To reduce the diameter of AL fibers, the mixing of water with a co-solvent that has lower surface tension is an easy way to reduce the surface tension of the spinning solution. It has been reported that the surface tension of sodium alginate (SA) aqueous solution could be decreased and electrospinnability could be improved with the addition of glycerol (Nie et al. 2008). Therefore, in this work, glycerol, a low-cost bioreagent with lower surface tension $(63.4 \mathrm{mN} / \mathrm{m})$, was used as a cosolvent. Figure $2 \mathrm{~b}$ shows that finer fibers with an average fiber diameter of $26.11 \pm 8 \mu \mathrm{m}$ could be produced at the ratio of glycerol to water of $0.5: 1 \mathrm{v} / \mathrm{v}$ (lignin: solvent $=1: 1.25$ w/w). With increasing the ratio of glycerol to water to $0.75: 1$ and $1: 1$, fused beaded fibers were obtained (Figs. 2c and 2d). These results were in line with the physical properties of AL solutions (Table 1). It can be seen that increasing glycerol content led to a significant 
decrease in conductivity and an increase in viscosity of the spinning solution (Nie et al. 2008).
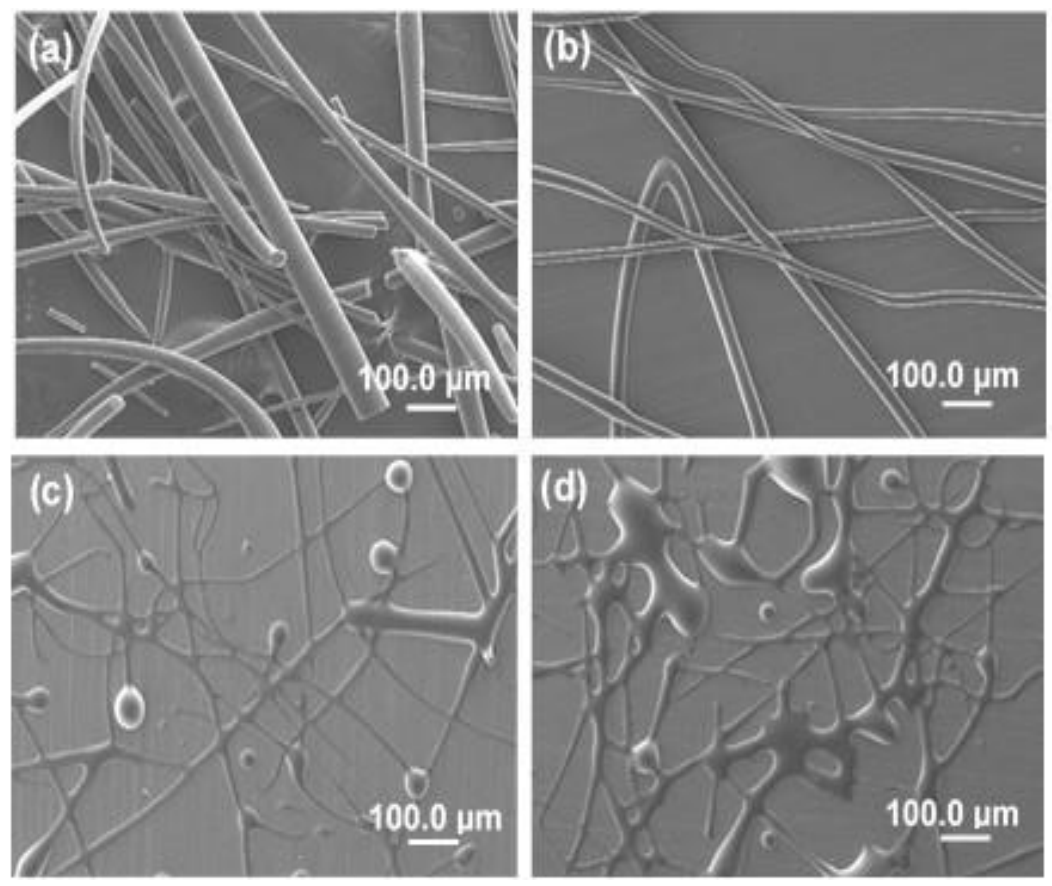

Fig. 2. SEM images of electrospun fibers produced from AL solutions: (a) in water (lignin:water = $1: 1.5 \mathrm{w} / \mathrm{w}$ ); and (b through d) in mixed glycerol/water solvent (lignin:solvent $=1: 1.25 \mathrm{w} / \mathrm{w}$ ); the ratios of glycerol to water in the mixed solvent were (b) $0.5: 1$; (c) $0.75: 1$; and (d) $1: 1 \mathrm{v} / \mathrm{v}$

Table 1. Physical Properties of AL Solutions

\begin{tabular}{|c|c|c|c|}
\hline $\begin{array}{c}\text { Glycerol:Water } \\
(\mathbf{v} / \mathbf{v})\end{array}$ & $\begin{array}{c}\text { AL:Solvent } \\
(\mathbf{w} / \mathbf{w})\end{array}$ & $\begin{array}{c}\text { Conductivity } \\
(\boldsymbol{\mu S} / \mathbf{c m})\end{array}$ & $\begin{array}{c}\text { Viscosity } \\
(\mathbf{P a} \cdot \mathbf{s})\end{array}$ \\
\hline $0: 1$ & $1: 1.5$ & $1086.29 \pm 97.66$ & $93.30 \pm 11.13$ \\
\hline $0.5: 1$ & $1: 1.25$ & $532.31 \pm 42.13$ & $\mathrm{n} / \mathrm{a}$ \\
\hline $0.75: 1$ & $1: 1.25$ & $463.38 \pm 28.16$ & $\mathrm{n} / \mathrm{a}$ \\
\hline $1: 1$ & $1: 1.25$ & $385.83 \pm 19.51$ & $1204.23 \pm 43.32$ \\
\hline
\end{tabular}

\section{Stabilized Fibers and CFs}

Figure 3 shows micrographs using visible light (for colors of CFs) and SEM images with histograms of the diameters of fibers obtained from electrospinning of AL solutions. The stabilized fibers showed considerably smaller fiber diameters compared with the lignin ones. A smooth fiber surface could be obtained from the stabilized fibers from the AL solution (Fig. 3a2), whereas the stabilized fibers from the glycerol-blended solution showed irregular morphological appearance because of the evaporation of glycerol (Fig. 3b2). The average fiber diameters (thickness) of CFs derived from solutions without and with glycerol co-solvent were $24.55 \pm 9 \mu \mathrm{m}(0.098 \mathrm{~mm})$ and $21.05 \pm 9 \mu \mathrm{m}(0.084 \mathrm{~mm})$. respectively. CFs obtained from both solutions were black in color, as shown in inset images in Figs. 3a and 3b. The surface of fibers became rough and uneven after the 
carbonization (Figs. 3a3 and 3b3). This irregular fiber surface may be attributed to the presence of contaminants caused by invisible inorganics (Song et al. 2019). The tensile strengths of commercial PAN-based carbon fiber are in the range of $3 \mathrm{GPa}$ to $7 \mathrm{GPa}$, while the tensile strength of typical lignin-based CF was only $0.48 \mathrm{GPa}$ (Lin et al. 2013). Despite the lower strength properties, lignin-based CFs have substantial potentials for the next generation of alternative electronic and electrode applications (Ma et al. 2016; Jayawickramage et al. 2019). Therefore, in this work, electrical property was the only focus. Electrical conductivities of CFs derived from lignin solutions without and with glycerol were $2.64 \pm 0.68 \mathrm{mS} / \mathrm{cm}$ and $5.38 \pm 0.18 \mathrm{mS} / \mathrm{cm}$, respectively. This result corresponds to the reported study that the conductivity of fibers increases with reducing fiber diameters (Zhao et al. 2018).
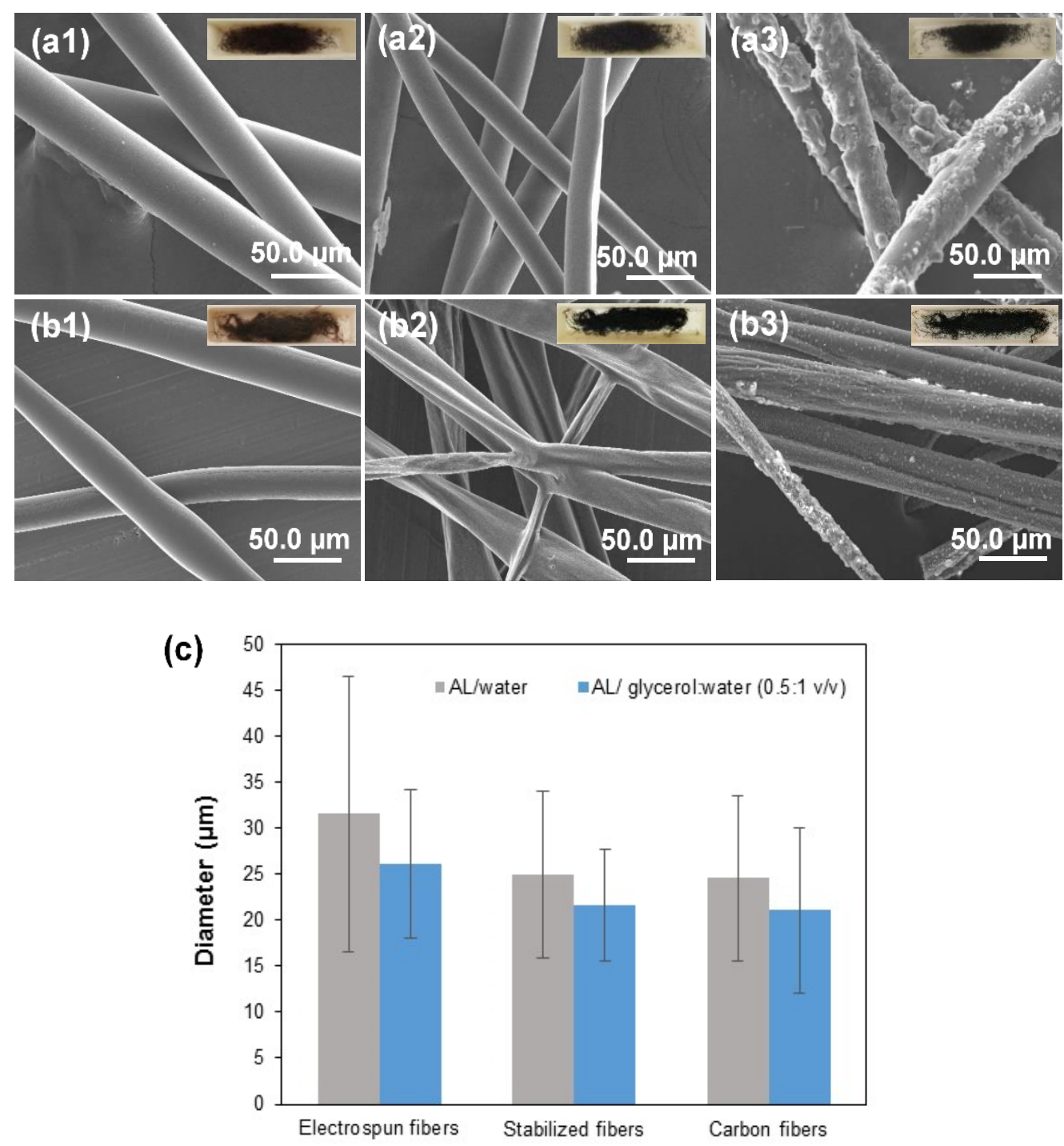

Fig. 3. SEM images of fibers from AL solutions: (a) in water (lignin:water $=1: 1.5 \mathrm{w} / \mathrm{w}$ ); (b) in mixed glycerol/water solvent (lignin:solvent $=1: 1.25 \mathrm{w} / \mathrm{w}$, glycerol: water $=0.5: 1 \mathrm{v} / \mathrm{v}$ ) (numbers 1 through 3 refer to electrospun fibers, stabilized fibers, and carbon fibers, respectively); and (c) histograms of the fiber diameters obtained (insets in (a) and (b) are photographic images of fibers in ceramic crucible boats) 


\section{Removal of Inorganic Contaminants from CFs}

Use of unpurified $\mathrm{AL}$ as a precursor for $\mathrm{CF}$ fabrications resulted in rough surfaces of CFs obtained due to the presence of inorganic contaminants. From the elemental composition investigation by EDS (Fig. S1), sodium (Na) and sulfur (S) were found as the major impurities in CFs. It should be noted that salts can be present in AL as a result of chemical processes that employ solvents and chemicals (e.g. $\mathrm{NaOH}$ and $\mathrm{Na}_{2} \mathrm{~S}$ ) during the the production (Srisasiwimon et al. 2018). The salt was still in the spinning solution during the electrospinning and remained in electrospun fibers after the solvent evaporation. When the electrospun fibers were heated through the thermal treatment processes (i.e. thermostabilization and carbonization) at low temperatures, the inorganic salts solidified and recrystallized on the fiber surface of the CFs obtained (Poursorkhabi et al. 2016). A previous study reported that $\mathrm{Na}$ content in $\mathrm{AL}$ could be reduced by acid washing (Hu and Hsieh 2013). Therefore, in this work, inorganic salts on the surface of CFs were removed by sulfuric acid $\left(\mathrm{H}_{2} \mathrm{SO}_{4}\right)$ washing by the following procedure. The CFs were stirred continuously in $5 \mathrm{wt} \% \mathrm{H}_{2} \mathrm{SO}_{4}$ aqueous solution for $4 \mathrm{~h}$. Water rinsing was then completed via stirring for $3 \mathrm{~h}$ (two times). After that, the CFs were oven-dried overnight. The SEM images of CFs before and after $\mathrm{H}_{2} \mathrm{SO}_{4}$ washing are shown in Fig. 4. The CFs after $\mathrm{H}_{2} \mathrm{SO}_{4}$ washing showed a smooth surface without contaminants (Figs. 4a2 and 4b2).

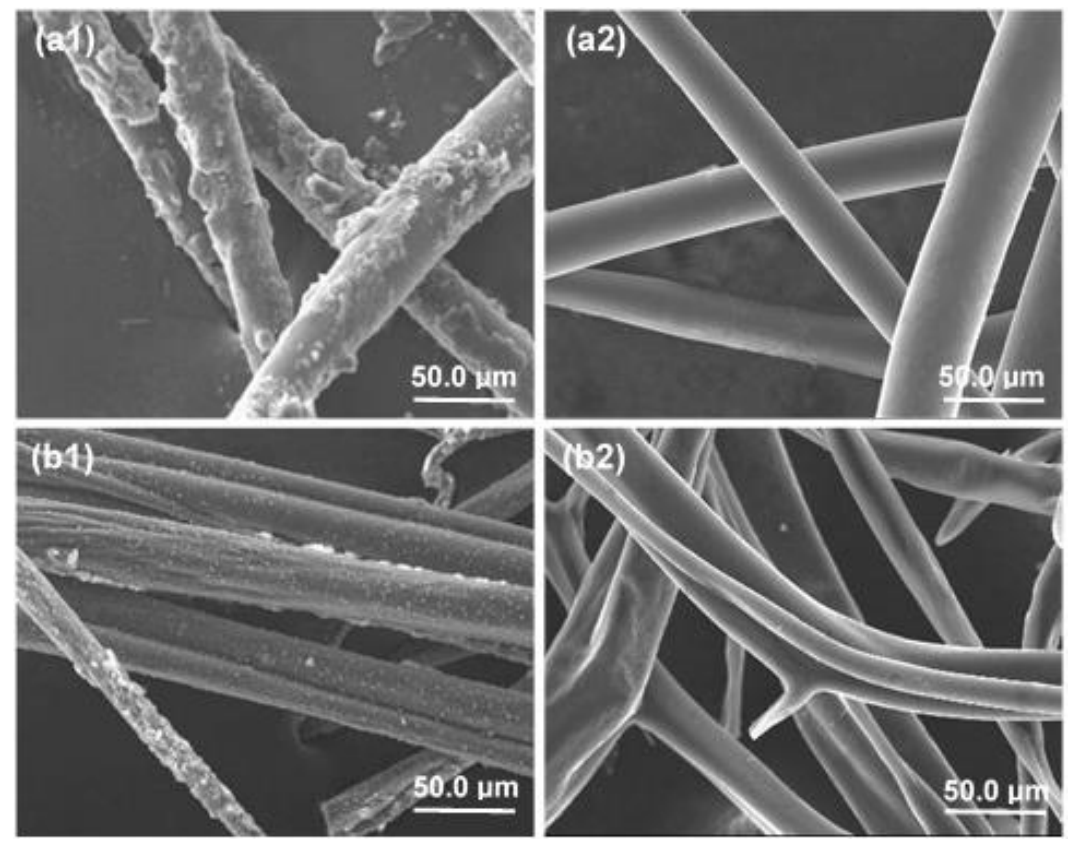

Fig. 4. SEM images of CFs from AL solutions: (a) in water (lignin:water $=1: 1.5 \mathrm{w} / \mathrm{w}$ ); and (b) in mixed glycerol/water solvent (lignin:solvent $=1: 1.25 \mathrm{w} / \mathrm{w}$, glycerol:water $=0.5: 1 \mathrm{v} / \mathrm{v}$ ); numbers " 1 " and "2" refer to before and after $\mathrm{H}_{2} \mathrm{SO}_{4}$ washing, respectively

Interestingly, the electrical conductivities of $\mathrm{CFs}$ after $\mathrm{H}_{2} \mathrm{SO}_{4}$ washing from the solutions without and with glycerol were $3.09 \pm 0.79 \mathrm{mS} / \mathrm{cm}$ and $6.07 \pm 0.16 \mathrm{mS} / \mathrm{cm}$, respectively, which were remarkably higher than the as-carbonized fibers $(17.0 \%$ and 12.8\% increments, respectively). Alarifi et al. (2015) stated that the electrical conductivities of PAN-derived CFs could also be improved after treatment by acids, which has potential to be utilized in strain sensor applications. From the viewpoint of conductivity, focusing on the change of conductivity after acid treatment, lignin-based 
carbon fibers may be applied in the sensing applications, e.g. chemical sensors. After treatment, the lignin-based carbon fibers have significant potentials for various applications, such as green electrode materials for electronic devices, printable cells, and energy storage applications.

The elemental compositional analysis by elemental analyzer (Table 2) revealed that after $\mathrm{H}_{2} \mathrm{SO}_{4}$ washing, the carbon contents of CFs from solution without and with glycerol increased from $61.43 \%$ to $80.99 \%$ and $59.47 \%$ to $81.01 \%$, respectively.

Table 2. Elemental Analysis ( $\mathrm{C}, \mathrm{H}, \mathrm{N}$, and $\mathrm{S}$ ) of CFs under Various Conditions of Raw Solutions before and after $\mathrm{H}_{2} \mathrm{SO}_{4}$ Washing

\begin{tabular}{|c|c|c|c|c|c|c|}
\hline \multicolumn{2}{|c|}{ Raw Solution for CFs } & \multirow{3}{*}{ Elemental Analysis of CFs (\%) } \\
\cline { 5 - 7 } $\begin{array}{c}\text { Lignin:Solvent } \\
(\mathbf{v} / \mathbf{v})\end{array}$ & $\begin{array}{c}\text { Solvent } \\
\text { (Glycerol:Water) }(\mathbf{v} / \mathbf{v})\end{array}$ & $\mathrm{H}_{2} \mathrm{SO}_{4}$ Washing & $\mathbf{N}$ & $\mathbf{C}$ & $\mathbf{H}$ & $\mathbf{S}$ \\
\hline $1: 1.5$ & $0: 1$ & Before & 0.23 & 59.47 & 1.46 & 3.18 \\
\hline $1: 1.5$ & $0: 1$ & After & 0.28 & 81.01 & 1.75 & 2.12 \\
\hline $1: 1.25$ & $0.5: 1$ & Before & 0.21 & 61.43 & 1.19 & 3.21 \\
\hline $1: 1.25$ & $0.5: 1$ & After & 0.26 & 80.99 & 1.62 & 2.32 \\
\hline
\end{tabular}

Note: Commercial AL powder consisted of $0.14 \% \mathrm{~N}, 46.55 \% \mathrm{C}, 4.82 \% \mathrm{H}$, and $4.0 \% \mathrm{~S}$

Chemical structures and functional groups of AL precursor and CFs were investigated by FTIR (Fig. 5). In all spectra, broad absorbance peaks in the range of 3390 to $3220 \mathrm{~cm}^{-1}$ indicating $\mathrm{O}-\mathrm{H}$ stretching vibration of hydroxyl groups (Zhao et al. 2016) and absorbed molecular water on fiber surfaces were observed. In the only-AL precursor spectrum, the O-H stretching peak was extended to the range of 3460 to $3220 \mathrm{~cm}^{-1}$, which was attributed to aliphatic and phenolic hydroxyl groups in the structure of lignin. Moreover, for AL precursor, the following were observed: bands in the range of 2930 to $2833 \mathrm{~cm}^{-1}$ (corresponding to the vibration of $\mathrm{C}-\mathrm{H}$ stretching of methyl and methylene groups) (El Mansouri et al. 2011); the vibrations of $\mathrm{C}-\mathrm{C}$ bonds and aliphatic $\mathrm{C}-\mathrm{H}, \mathrm{C}-\mathrm{O}$, and $\mathrm{C}-\mathrm{O}-\mathrm{C}$ groups at 1500 to $1000 \mathrm{~cm}^{-1}$; aromatic skeletal vibrations at $1578,1505,1464$ and $1420 \mathrm{~cm}^{-1}$ (indicating an aromatic functionality of lignin); and peaks in the 900 to 700 $\mathrm{cm}^{-1}$ range (indicating $\mathrm{C}-\mathrm{H}$ deformation in benzene ring) (Srisasiwimon et al. 2018). Considering FTIR spectra of CFs compared with AL precursor, new bands appeared at $2360 \mathrm{~cm}^{-1}$ for CFs, arising from the adsorption of environmental $\mathrm{CO}_{2}$ (Ray et al. 2004). Meanwhile, the four spectra of CFs showed disappearances of aromatic skeletal vibrations, $\mathrm{O}-\mathrm{H}$ stretching, $\mathrm{C}-\mathrm{H}$ stretching, $\mathrm{C}-\mathrm{H}$ deformation $\left(1384 \mathrm{~cm}^{-1}\right)$, and $\mathrm{C}-\mathrm{O}$ stretching (1263 $\left.\mathrm{cm}^{-1}\right)$. This result corresponds to the decomposition of the majority of lignin side chains after burning at a temperature over $500{ }^{\circ} \mathrm{C}$ (Cao et al. 2013; Zhang et al. 2017; Zhao et al. 2018). Carbonization can reduce $\mathrm{O}-\mathrm{H}, \mathrm{C}-\mathrm{H}, \mathrm{C}-\mathrm{O}$, and phenyl groups, induce closer structures of benzene rings, create cross-links, and finally change the structure to be the network of carbon-six rings (Lin et al. 1995; Edie 1998). 


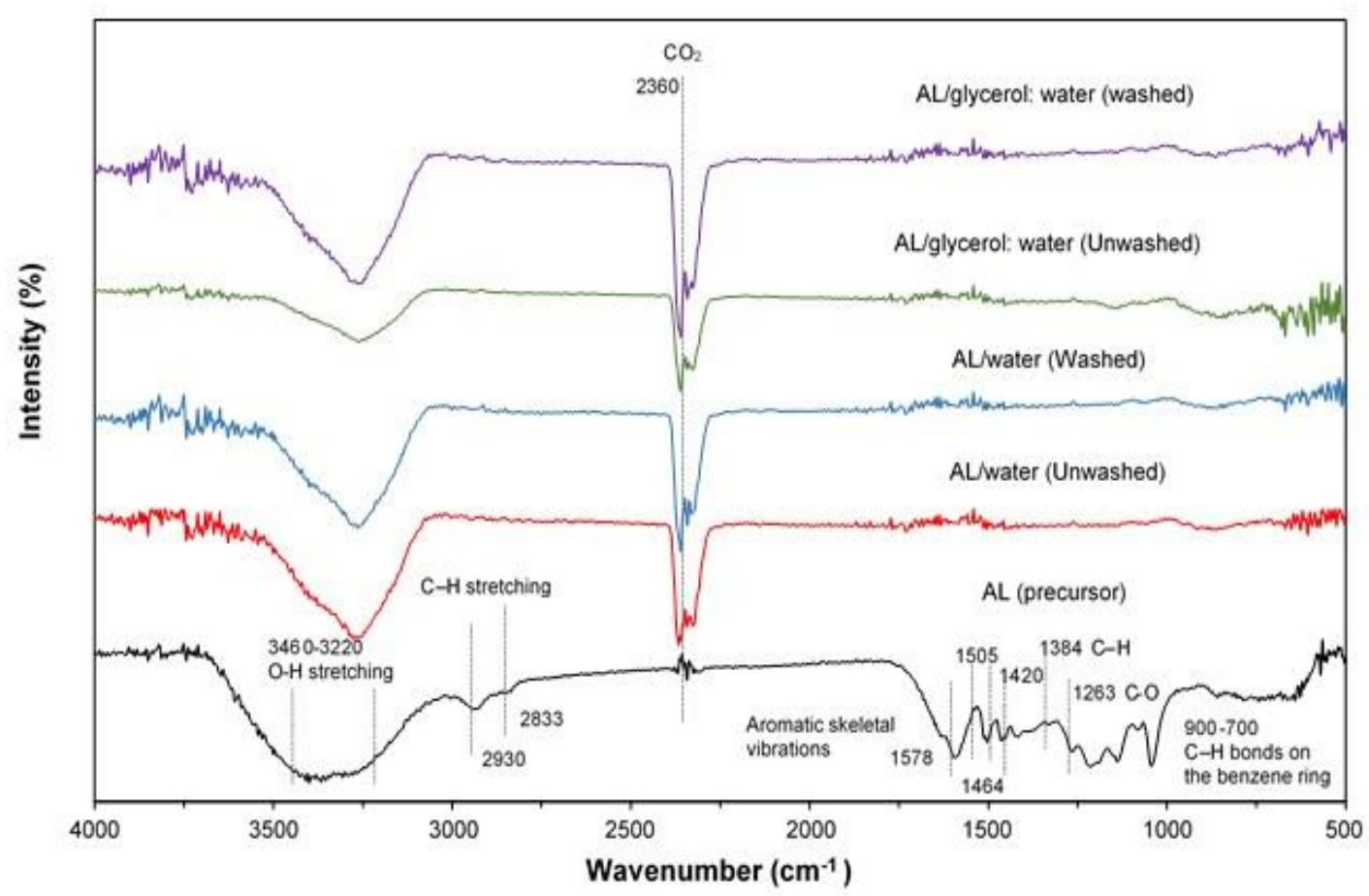

Fig. 5. FTIR spectra of $A L$ precursor and CFs before and after $\mathrm{H}_{2} \mathrm{SO}_{4}$ washing from $A L$ solutions in water (lignin:water $=1: 1.5 \mathrm{w} / \mathrm{w}$ ) and in mixed glycerol/water solvent (lignin:solvent $=1: 1.25$ $\mathrm{w} / \mathrm{w}$, glycerol:water $=0.5: 1 \mathrm{v} / \mathrm{v}$ )

\section{Specific Surface Area and Pore Characterizations of CFs}

$\mathrm{N}_{2}$ adsorption isotherms of $\mathrm{CFs}$ were used for determination of surface area (Brunauer-Emmett-Teller (BET) method), and $\mathrm{N}_{2}$ desorption was used for the estimation of pore size and pore volume (Barrett-Joyner-Halenda (BJH) method) of CFs before and after $\mathrm{H}_{2} \mathrm{SO}_{4}$ washing. Type-IV adsorption-desorption isotherms were found from all samples (Fig. S2), revealing mesoporous structure (meaning that pore sizes are in the range of 2 to $50 \mathrm{~nm}$ ) with strong adsorbent interactions (Sing 1985; Chen et al. 2014). The pore characteristics of CFs testes are listed in Table 3. It was found that CFs derived from AL solutions without glycerol before $\mathrm{H}_{2} \mathrm{SO}_{4}$ washing had the lowest specific surface area $\left(33.89 \mathrm{~m}^{2} / \mathrm{g}\right)$, the largest pore size $(4.19 \mathrm{~nm})$, and the smallest pore volume $\left(0.035 \mathrm{~cm}^{3} / \mathrm{g}\right)$. This result might be caused by obstruction of gas adsorption and desorption by inorganic salt crystals contained on the rough surface of fibers. After $\mathrm{H}_{2} \mathrm{SO}_{4}$ washing, BET specific surface area and pore volume of CFs derived from both AL solutions (with and without glycerol) were found to significantly increase, while pore size was found to decrease. The highest specific surface area of $85.67 \mathrm{~m}^{2} / \mathrm{g}$ and pore volume of $0.072 \mathrm{~cm}^{3} / \mathrm{g}$ were achieved from CFs derived from $\mathrm{AL}$ solutions with glycerol after $\mathrm{H}_{2} \mathrm{SO}_{4}$ washing (while the specific surface area and pore volume of CFs derived from AL solutions without glycerol after $\mathrm{H}_{2} \mathrm{SO}_{4}$ washing were $83.41 \mathrm{~m}^{2} / \mathrm{g}$ and $0.062 \mathrm{~cm}^{3} / \mathrm{g}$, respectively, corresponding to the thinner fiber diameters) (Jayawickramage et al. 2019). Even though the specific surface areas of CFs derived from AL in this work were lower than PAN-based CFs (700 to 1,200

$\mathrm{m}^{2} / \mathrm{g}$ ) (Inagaki et al. 2012) and cellulose/polymer-derived-activated CFs $\left(870-1,400 \mathrm{~m}^{2} / \mathrm{g}\right.$ ) (Ogale et al. 2016), the surface areas of AL-derived CFs were still higher than the CF mats derived from organosolv lignin $\left(8-37 \mathrm{~m}^{2} / \mathrm{g}\right.$ ) (Tenhaeff et al. 2014). CFs derived from AL 
in this work are still promising as a starting point for future studies in many advanced applications such as electrochemical energy storage and electrode applications.

Table 3. Surface Area and Pore Characteristics of CFs Fabricated from Various Conditions of Raw Solutions before and after $\mathrm{H}_{2} \mathrm{SO}_{4}$ Washing

\begin{tabular}{|c|c|c|c|c|c|}
\hline \multicolumn{2}{|c|}{ Raw Solution for CFs } & \multirow{2}{*}{$\mathbf{H}_{2} \mathbf{S O}_{4}$} & BET Surface \\
\cline { 1 - 2 } $\begin{array}{c}\text { Lignin:Solvent } \\
(\mathbf{v} / \mathbf{v})\end{array}$ & $\begin{array}{c}\text { Solvent } \\
(\text { Glycerol:Water }) \\
(\mathbf{v} / \mathbf{v})\end{array}$ & Washing & $\begin{array}{c}\text { Pore Size } \\
\text { Area }\left(\mathbf{m}^{2} \mathbf{~ g}^{-1}\right)\end{array}$ & $\begin{array}{c}\text { Pore Volume } \\
\left(\mathbf{c m}^{3} \mathbf{~ g}^{-1}\right)\end{array}$ \\
\hline $1: 1.5$ & $0: 1$ & Before & 33.89 & 4.19 & 0.035 \\
\hline $1: 1.5$ & $0: 1$ & After & 83.41 & 3.43 & 0.062 \\
\hline $1: 1.25$ & $0.5: 1$ & Before & 65.99 & 3.75 & 0.060 \\
\hline $1: 1.25$ & $0.5: 1$ & After & 85.67 & 2.97 & 0.072 \\
\hline
\end{tabular}

\section{CONCLUSIONS}

1. Electrospun fibers with smooth surfaces and fine morphologies from pure AL solutions were successfully produced by electrospinning using a simple heated single spinneret system.

2. With mixing of small amount of glycerol as a co-solvent in AL solutions, smooth fibers with smaller diameters were achieved due to decreased surface tension of the spinning solution and improved electrospinnability.

3. The fibers obtained were successfully converted into CFs with a rough and uneven surface via thermal processes. The CFs derived from glycerol-added solution showed greater electrical conductivity, specific surface area, and porosity compared with those from the pure AL solution.

4. Inorganic salts on the surface of CFs were successfully removed via $\mathrm{H}_{2} \mathrm{SO}_{4}$ washing. The electrical conductivity, specific surface area, and porosity of $\mathrm{CFs}$ after $\mathrm{H}_{2} \mathrm{SO}_{4}$ washing was obviously improved.

5. This study provides a new solution to solve the problem of electrospinning of pure AL and demonstrated an approach to produce low-cost CFs from a promising bio-based precursor. The derived CFs are promising for the further uses in electronic devices and electrode applications.

\section{ACKNOWLEDGMENTS}

This study was financially supported by the Joint Graduate School of Energy and Environment (No. JGSEE/THESIS/278), and Petchra Pra Jom Klao Master Scholarship of King Mongkut's University of Technology Thonburi (No. 34/2559). The authors would like to thank the Thailand Research Fund (RSA6180085), and Japan Science and 
Technology Agency [Collaboration Hubs for International Research Program (CHIRP) within the framework of the Strategic International Collaborative Research Program (SICORP)] for partly supporting this work. The authors are also very thankful to the Graduate School of Energy Science, Kyoto University, for providing characterization instruments.

\section{REFERENCES CITED}

Adam, H. (1997). "Carbon fibre in automotive applications," Materials \& Design 18(46), 349-355. DOI: 10.1016/S0261-3069(97)00076-9

Ago, M., Okajima, K., Jakes, J. E., Park, S., and Rojas, O. J. (2012). “Lignin-based electrospun nanofibers reinforced with cellulose nanocrystals," Biomacromolecules 13(3), 918-926. DOI: 10.1021/bm201828g

Alarifi, I., Alharbi, A., Khan, W., Swindle, A., and Asmatulu, R. (2015). "Thermal, electrical and surface hydrophobic properties of electrospun polyacrylonitrile nanofibers for structural health monitoring," Materials 8(10), 7017-7031. DOI: 10.3390/ma8105356

Baker, D. A., and Rials, T. G. (2013). "Recent advances in low-cost carbon fiber manufacture from lignin," Journal of Applied Polymer Science 130(2), 713-728. DOI: 10.1002/app.39273

Berenguer, R., García-Mateos, F. J., Ruiz-Rosas, R., Cazorla-Amorós, D., Morallón, E., Rodríguez-Mirasol, J., and Cordero, T. (2016). "Biomass-derived binderless fibrous carbon electrodes for ultrafast energy storage," Green Chemistry 18(6), 1506-1515. DOI: 10.1039/C5GC02409A

Cao, J., Xiao, G., Xu, X., Shen, D., and Jin, B. (2013). "Study on carbonization of lignin by TG-FTIR and high-temperature carbonization reactor," Fuel Processing Technology 106, 41-47. DOI: 10.1016/j.fuproc.2012.06.016

Chen, C., Kang, Y., Huo, Z., Zhu, Z., Huang, W., Xin, H. L., Snyder, J. D., Li, D., Herron, J. A., Mavrikakis, M., and Chi, M. (2014). "Highly crystalline multimetallic nanoframes with three-dimensional electrocatalytic surfaces. Science 343(6177), 1339-1343. DOI:10.1126/science. 1249061

Chen, M. C.-W. (2014). Commercial Viability Analysis of Lignin Based Carbon Fibre, Master's Thesis, University of Simon Fraser, B.C., Canada.

Chuangchote, S., Sagawa, T., and Yoshikawa, S. (2009). "Electrospinning of poly(vinyl pyrrolidone): Effects of solvents on electrospinnability for the fabrication of poly(pphenylene vinylene) and $\mathrm{TiO}_{2}$ nanofibers," Journal of Applied Polymer Science 114(5), 2777-2791. DOI: 10.1002/app.30637

Dai, Z., Shi, X., Liu, H., Li, H., Han, Y., and Zhou, J. (2018). "High-strength ligninbased carbon fibers via a low-energy method," RSC Advances 8(3), 1218-1224. DOI: 10.1039/C7RA10821D

Dallmeyer, I., Ko, F., and Kadla, J. F. (2010). "Electrospinning of technical lignins for the production of fibrous networks," Journal of Wood Chemistry and Technology 30(4), 315-329. DOI:10.1080/02773813.2010.527782

Dallmeyer, I., Lin, L. T., Li, Y., Ko, F., and Kadla, J. F. (2014). "Preparation and characterization of interconnected, kraft lignin-based carbon fibrous materials by electrospinning," Macromolecular Materials and Engineering 299(5), 540-551. DOI:10.1002/mame.20130014 
Duval, A., and Lawoko, M. (2014). "A review on lignin-based polymeric, micro- and nano-structured materials," Reactive and Functional Polymers 85, 78-96. DOI: 10.1016/j.reactfunctpolym.2014.09.017

Edie, D. D. (1998). "The effect of processing on the structure and properties of carbon fibers," Carbon 36(4), 345-362. DOI: 10.1016/S0008-6223(97)00185-1

El Mansouri, N. E., Yuan, Q., and Huang, F. (2011). "Characterization of alkaline lignins for use in phenol-formaldehyde and epoxy resins," BioResources 6(3), 2647-2662. DOI: 10.15376/biores.6.3.2647-2662

Frank, E., Steudle, L. M., Ingildeev, D., Spörl, J. M., and Buchmeiser, M. R. (2014). "Carbon fibers: Precursor systems, processing, structure, and properties," Angewandte Chemie International Edition 53(21), 5262-5298. DOI: 10.1002/anie.201306129

$\mathrm{Hu}$, S., and Hsieh, Y.-L. (2013). "Ultrafine microporous and mesoporous activated carbon fibers from alkali lignin," Journal of Materials Chemistry A 1(37), 1127911288. DOI: 10.1039/C3TA12538F

Inagaki, M., Yang, Y., and Kang, F. (2012). "Carbon nanofibers prepared via electrospinning," Advanced Materials 24(19), 2547-2566. DOI: 10.1002/adma.201104940

Jacob, A. (2014). "Carbon fibre and cars - 2013 in review," Reinforced Plastics 58(1), 18-19. DOI: 10.1016/S0034-3617(14)70036-0

Javaid, A. (2017). "11- Activated carbon fiber for energy storage," in: Activated Carbon Fiber and Textiles, J. Y. Chen (ed.), Woodhead Publishing, Oxford, England, pp. 281-303.

Jayawickramage, R. A. P, Balkus, K. J., and Ferraris, J. P. (2019). "Binder free carbon nanofiber electrodes derived from polyacrylonitrile-lignin blends for high performance supercapacitors," Nanotechnology 30(35), 355402. DOI:10.1088/13616528/ab2274

Jin, J., Yu, B.-J., Shi, Z.-Q., Wang, C.-Y., and Chong, C.-B. (2014). "Lignin-based electrospun carbon nanofibrous webs as free-standing and binder-free electrodes for sodium ion batteries," Journal of Power Sources 272, 800-807. DOI:

10.1016/j.jpowsour.2014.08.119

Kai, D., Jiang, S., Low, Z. W., and Loh, X. J. (2015). "Engineering highly stretchable lignin-based electrospun nanofibers for potential biomedical applications," Journal of Materials Chemistry B 3(30), 6194-6204. DOI: 10.1039/C5TB00765H

Lin, L., Li, Y., and Ko, F. K. (2013). "Fabrication and properties of lignin based carbon nanofiber," Journal of Fiber Bioengineering and Informatics 6(4), 335-347. DOI: 10.3993/jfbi12201301

Lin, L., Yoshioka, M., Yao, Y., and Shiraishi, N. (1995). "Physical properties of moldings from liquefied wood resins," Journal of Applied Polymer Science 55(11), 1563-1571. DOI: 10.1002/app.1995.070551107

Lora, J. H., and Glasser, W. G. (2002). "Recent industrial applications of lignin: A sustainable alternative to nonrenewable materials," Journal of Polymers and the Environment 10(1-2), 39-48. DOI: 10.1023/a:1021070006895

Ma, A., Zhou, L., and Chang, J. (2015). "Conversion of lignin-nanofibers to CNFs," Nano 10(6), Article ID 1550092. DOI: 10.1142/s1793292015500927

Ma, X., Kolla, P., Zhao, Y., Smirnova, A. L., and Fong, H. (2016). "Electrospun ligninderived carbon nanofiber mats surface-decorated with $\mathrm{MnO}_{2}$ nanowhiskers as binder- 
free supercapacitor electrodes with high performance," Journal of Power Sources 325, 541-548. DOI:10.1016/j.jpowsour.2016.06.073

Matsuo, T. (2008). "Fibre materials for advanced technical textiles," Textile Progress 40(2), 87-121. DOI: 10.1080/00405160802133028

Nie, H., He, A., Zheng, J., Xu, S., Li, J., and Han, C. C. (2008). "Effects of chain conformation and entanglement on the electrospinning of pure alginate," Biomacromolecules 9(5), 1362-1365. DOI: 10.1021/bm701349j

Norberg, I., Nordström, Y., Drougge, R., Gellerstedt, G., and Sjöholm, E. (2013). “A new method for stabilizing softwood kraft lignin fibers for carbon fiber production," Journal of Applied Polymer Science 128(6), 3824-3830. DOI:10.1002/app.38588

Ogale, A. A., Zhang, M., and Jin, J. (2016). "Recent advances in carbon fibers derived from biobased precursors," Journal of Applied Polymer Science 133(45). DOI:10.1002/app.43794

Poursorkhabi, V., Mohanty, A. K., and Misra, M. (2015). "Electrospinning of aqueous lignin/poly(ethylene oxide) complexes," Journal of Applied Polymer Science 132(2), Article Number 41260. DOI: 10.1002/app.41260

Poursorkhabi, V., Mohanty, A. K., and Misra, M. (2016). "Statistical analysis of the effects of carbonization parameters on the structure of carbonized electrospun organosolv lignin fibers," Journal of Applied Polymer Science 133(45), 44005. DOI:10.1002/app.44005

Ray, S. C., Bose, B., Chiou, J. W., Tsai, H. M., Jan, J. C., Kumar, K., Pong, W. F., DasGupta, D., Fanchini, G., and Tagliaferro, A. (2004). "Deposition and characterization of diamond-like carbon thin films by electro-deposition technique using organic liquid," Journal of Materials Research 19(4), 1126-1132.

DOI:10.1557/JMR.2004.0146

Ruiz-Rosas, R., Bedia, J., Lallave, M., Loscertales, I. G., Barrero, A., Rodríguez-Mirasol, J., and Cordero, T. (2010). "The production of submicron diameter carbon fibers by the electrospinning of lignin," Carbon 48(3), 696-705. DOI:

10.1016/j.carbon.2009.10.014

Schreiber, M., Vivekanandhan, S., Cooke, P., Mohanty, A. K., and Misra, M. (2014). "Electrospun green fibres from lignin and chitosan: A novel polycomplexation process for the production of lignin-based fibres," Journal of Materials Science 49(23), 7949-7958. DOI: 10.1007/s10853-014-8481-z

Sen, S., Patil, S., and Argyropoulos, D. S. (2015). "Thermal properties of lignin in copolymers, blends, and composites: A review," Green Chemistry 17(11), 4862-4887. DOI: $10.1039 / \mathrm{C} 5 \mathrm{GC} 01066 \mathrm{G}$

Sing, K. S. (1985). "Reporting physisorption data for gas/solid systems with special reference to the determination of surface area and porosity (Recommendations 1984)," Pure and applied chemistry 57(4), 603-619. DOI: 10.1515/iupac.57.0007

Song, M., Yu, L., Song, B., Meng, F., and Tang, X. (2019). "Alkali promoted the adsorption of toluene by adjusting the surface properties of lignin-derived carbon fibers," Environmental Science and Pollution Research 26(22), 22284-22294. DOI: 10.1007/s11356-019-05456-9

Srisasiwimon, N., Chuangchote, S., Laosiripojana, N., and Sagawa, T. (2018). " $\mathrm{TiO}_{2} /$ lignin-based carbon composited photocatalysts for enhanced photocatalytic conversion of lignin to high value chemicals," ACS Sustainable Chemistry \& Engineering 6(11), 13968-13976. DOI: 10.1021/acssuschemeng.8b02353 
Svinterikos, E., and Zuburtikudis, I. (2016). "Carbon nanofibers from renewable bioresources (lignin) and a recycled commodity polymer [poly(ethylene terephthalate)]," Journal of Applied Polymer Science 133(37), 43936. DOI: 10.1002/app.43936

Tenhaeff, W. E., Rios, O., More, K., and McGuire, M. A. (2013). "Highly robust lithium ion battery anodes from lignin: an abundant, renewable, and low-cost material," Advanced Functional Materials 24(1), 86-94. DOI: 10.1002/adfm.201301420

Thiruvenkatachari, R., Su, S., An, H., and Yu, X. X. (2009). "Post combustion $\mathrm{CO}_{2}$ capture by carbon fibre monolithic adsorbents," Progress in Energy and Combustion Science 35(5), 438-455. DOI: 10.1016/j.pecs.2009.05.003

Wang, S.-X., Yang, L., Stubbs, L. P., Li, X., and He, C. (2013). "Lignin-derived fused electrospun carbon fibrous mats as high performance anode materials for lithium ion batteries," ACS Applied Materials and Interfaces 5(23), 12275-12282. DOI: 10.1021/am4043867

Yang, S., Xiao, T., Zhang, J., Chen, Y., and Li, L. (2015). "Activated carbon fiber as heterogeneous catalyst of peroxymonosulfate activation for efficient degradation of acid orange 7 in aqueous solution," Separation and Purification Technology 143, 1926. DOI: 10.1016/j.seppur.2015.01.022

Zhang, L., and Hsieh, Y.-L. (2009). "Carbon nanofibers with nanoporosity and hollow channels from binary polyacrylonitrile systems," European Polymer Journal 45(1), 47-56. DOI: 10.1016/j.eurpolymj.2008.09.035

Zhang, X., Yan, Q., Leng, W., Li, J., Zhang, J., Cai, Z., and Hassan, E. (2017). "Carbon nanostructure of kraft lignin thermally treated at 500 to 1000 C," Materials 10(8), 975. DOI: $10.3390 / \mathrm{ma} 10080975$

Zhao, M., Meng, L., Ma, L., Wu, G., Wang, Y., Xie, F., and Huang, Y. (2016). "Interfacially reinforced carbon fiber/epoxy composites by grafting melamine onto carbon fibers in supercritical methanol," RSC Advances 6(35), 29654-29662. DOI: 10.1039/C6RA00570E

Zhao, Y., Liu, Y., Tong, C., Ru, J., Geng, B., Ma, Z., Liu, H., and Wang, L. (2018). "Flexible lignin-derived electrospun carbon nanofiber mats as a highly efficient and binder-free counter electrode for dye-sensitized solar cells," Journal of Materials Science 53(10), 7637-7647. DOI: 10.1007/s10853-018-2059-0

Article submitted: August 21, 2019; Peer review completed: October 26, 2019; Revisions accepted: February 10, 2020; Published: February 11, 2020.

DOI: 10.15376/biores.15.2. 2412-2427 


\section{APPENDIX}

\section{Supplementary Information}

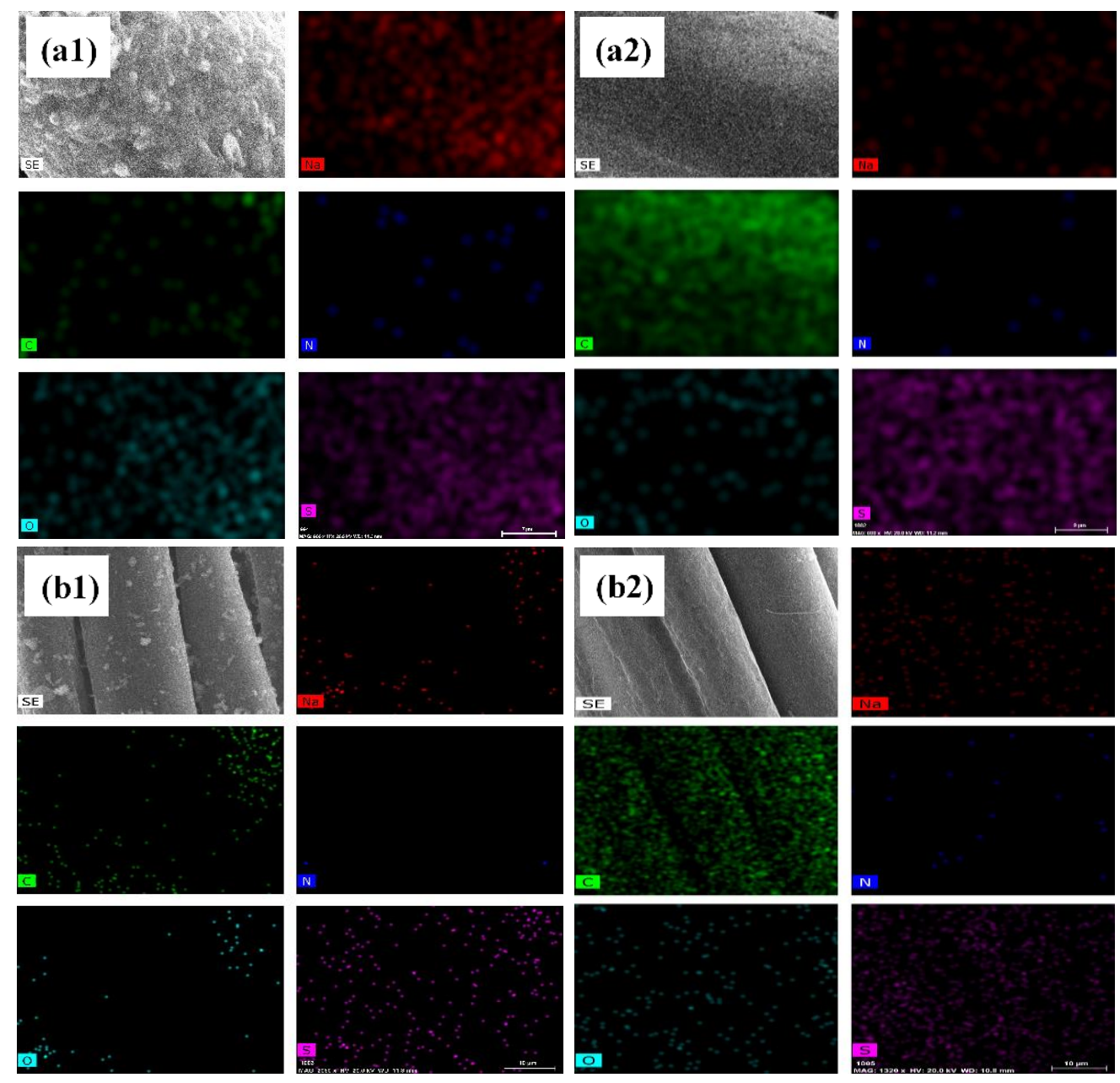

Fig. S1. EDS element mapping of CFs from AL solutions: (a) in water (lignin:water $=1: 1.5 \mathrm{w} / \mathrm{w}$ ) and (b) in mixed glycerol/water solvent (lignin:solvent $=1: 1.25 \mathrm{w} / \mathrm{w}$, glycerol:water $=0.5: 1 \mathrm{v} / \mathrm{v}$ ); numbers " 1 " and " 2 " refer to before and after $\mathrm{H}_{2} \mathrm{SO}_{4}$ washing, respectively 


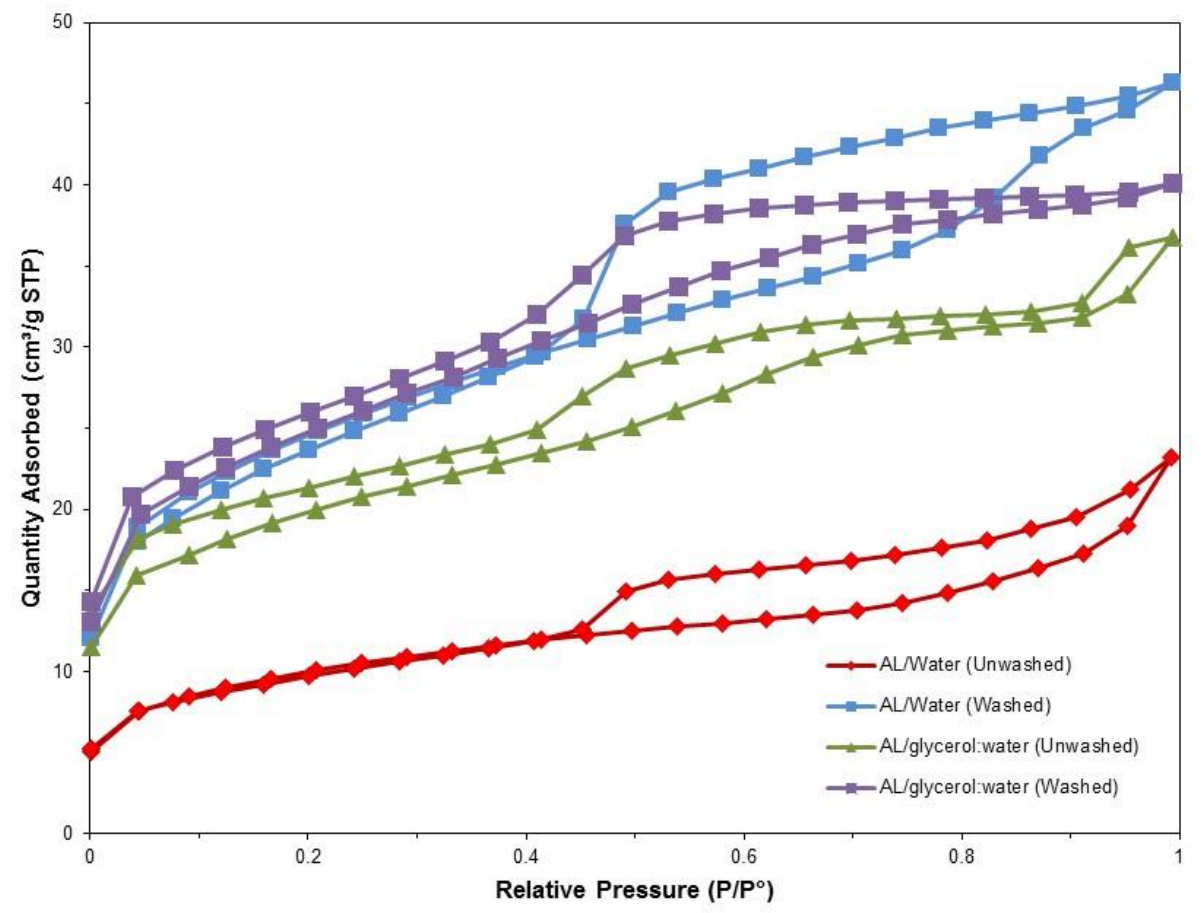

Fig. S2. Nitrogen adsorption-desorption isotherm of CFs before and after $\mathrm{H}_{2} \mathrm{SO}_{4}$ washing from $\mathrm{AL}$ solutions in water (lignin:water $=1: 1.5 \mathrm{w} / \mathrm{w}$ ) and in mixed glycerol/water solvent (lignin:solvent = $1: 1.25 \mathrm{w} / \mathrm{w}$, glycerol:water $=0.5: 1 \mathrm{v} / \mathrm{v}$ ) 